\title{
HEART RATE AND ESTIMATED ENERGY EXPENDITURE DURING BALLROOM DANCING
}

\author{
B. A. BLANKSBY and P. W. REIDY
}

Department of Human Movement and Recreation Studies, University of Western Australia

\section{ABSTRACT}

Ten competitive ballroom dance couples performed simulated competitive sequences of Modern and Latin American dance. Heart rate was telemetered during the dance sequences and related to direct measures of oxygen uptake and heart rate obtained while walking on a treadmill. Linear regression was employed to estimate gross and net energy expenditures of the dance sequences. A multivariate analysis of variance with repeated measures on the dance factor was applied to the data to test for interaction and main effects on the sex and dance factors. Overall mean heart rate values for the Modern dance sequence were 170 beats. $\mathrm{min}^{-1}$ and 173 beats. $\mathrm{min}^{-1}$ for males and females respectively. During the Latin American sequence

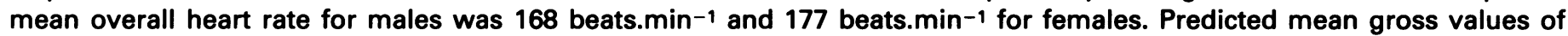

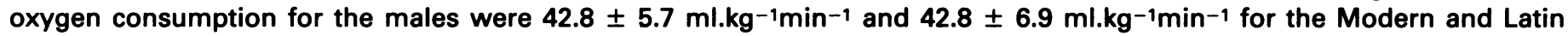
American sequences respectively. Corresponding gross estimates of oxygen consumption for the females were $34.7 \pm$ $3.8 \mathrm{ml} . \mathrm{kg}^{-1} \mathrm{~min}^{-1}$ and $36.1 \pm 4.1 \mathrm{ml}^{\mathrm{kg}} \mathrm{kg}^{-1} \mathrm{~min}^{-1}$. Males were estimated to expend $54.1 \pm 8.1 \mathrm{~kJ}^{\mathrm{min}} \mathrm{mi}^{-1}$ of energy during the Modern sequence and $54.0 \pm 9.6 \mathrm{~kJ}$. min-1 during the Latin American sequence, while predicted energy expediture for females was $34.7 \pm 3.8 \mathrm{~kJ} . \mathrm{min}^{-1}$ and $36.1 \pm 4.1 \mathrm{~kJ} . \mathrm{min}^{-1}$ for Modern and Latin American dance respectively. The results suggested that both males and females were dancing at greater than $80 \%$ of their maximum oxygen consumption. A significant difference between males and females was observed for predicted gross and net values of oxygen consumption (in L.min-1 and $\mathrm{ml}^{.} \mathrm{kg}^{-1} \mathrm{~min}^{-1}$ ).

Key words: Dancing, Heart rate, Energy expenditure

\section{INTRODUCTION}

Ballroom dancing currently is enjoying a resurgence of public interest in Australia. In addition to casual participation there are groups of dedicated competitive dancers who undertake rigorous training and pursue competitive programmes. These individuals appear to be performing at very high levels of energy expenditure throughout their competitive dance routines. A more thorough understanding of the energy demands of competition would enable the prescribing of more specific training programmes to ensure that a lack of adequate fitness does not detract from performance. Similarly, dancing several times per week can make a valuable training contribution to total energy expenditure of persons seeking to use this enjoyable social activity to enhance their level of fitness.

Since oxygen demand is difficult to measure directly during competitive dance performance, this study relies on the relationship which has previously been established between heart rate (HR) and oxygen consumption $\left(\mathrm{VO}_{2}\right.$ during submaximal exercise (Wyndham et al., 1959; Asstrand and Saltin, 1961; Molhotra et al, 1963; Andrews, 1967; Datta and Ramanathan, 1969). During low-intensity work a linear function fits both oxygen uptake and HR plots against workload, but at high workloads the curve has been described as an exponential function. The oxygen uptake curve reaches its asymptote more slowly than does HR. Hence, if $H R$ is plotted against oxygen uptake and a straight line fitted and extrapolated to the maximal values of $H R$, the oxygen uptake at this value is an underestimate of the actual measured oxygen uptake. However, the curve is described as linear up to the point when HR reached a maximal value (Wyndham et al, 1959).

Address for correspondence:

Assoc. Prof. B. A. Blanksby

Department of Human Movement and Recreation Studies

The University of Western Australia

Nedlands, W.A. 6009

Australia
The validity of $H R$ as an indicator of physiological strain has also been reported by Maxfield and Brouha (1963). Heart rate responses have been used to estimate energy expenditure or physiological strain in gymnastics (Favia and Phillips, 1970); athletics (Bowles and Sigerseth, 1968); basketball (Ramsey et al, 1970), and squash (Blanksby et al, 1973).

The purpose of this study was to predict the energy requirements of competitive Modern and Latin American ballroom dancing from telemetered HR while dancing simulated competitive sequences and relating back to direct measures of $\mathrm{VO}_{2}$ and $\mathrm{HR}$ previously recorded.

\section{METHODS}

\section{Subjects}

Ten competitive ballroom dance couples (A-grade amateur or qualified professionals) from the Wrightson Dance Studio in Perth, Western Australia served as subjects for this study. The mean physical characteristics of the subjects are listed in Table I.

TABLE I

Physical characteristics of the subjects

\begin{tabular}{|c|c|c|c|c|}
\hline & \multicolumn{2}{|c|}{ Males $(n=10)$} & \multicolumn{2}{|c|}{ Females $(n=10)$} \\
\hline & Mean & S.D. & Mean & S.D \\
\hline Age (yrs) & 23.2 & 6.3 & 21.8 & 6.0 \\
\hline Height (cm) & 176.8 & 6.3 & 165.4 & 4.2 \\
\hline Weight (kg) & 60.5 & 5.6 & 57.7 & 5.5 \\
\hline Body fat (\%) & 10.3 & 1.0 & 20.8 & 3.0 \\
\hline Fat free mass (kg) & 54.3 & 5.1 & 45.6 & 3.4 \\
\hline
\end{tabular}

\section{Test Protocol}

Subjects attended two formal testing sessions after having been made familiar with test procedures. Laboratory tests were administered in the laboratory of the Department of Human Movement and Recreation Studies at the University of Western Australia, and the dance sequence telemetry 
tests were carried out at the Wrightson Dance Studio, Murray Street, Perth. The ambient temperature of both venues was within the accepted critical range of $18^{\circ} \mathrm{C}$ to $22^{\circ} \mathrm{C}$ dry bulb temperature and relative humidity less than $60 \%$ (Andérson et al, 1971).

The first session involved the recording of height, weight, per cent body fat, fat free mass and resting and maximal values for $\mathrm{HR}$ and $\mathrm{VO}_{2}$. Body fat content was estimated from skinfold thicknesses using the Yuhasz equation (1962) for males and the Sloan-Weir formula (1970) for females. Fat free mass was derived by converting the percentage of body fat to the equivalent percentage of total body weight, then subtracting this value from total body weight. Resting metabolism was measured in the sitting position after the subject had rested in the supine position for 25 minutes. A Koegal ' $Y$ ' Respiratory Valve and 120-litre Collins Chain Compensated Gasometer were used to collect the expired air and measure pulmonary ventilation. Samples of the expired air were drawn into a 2litre balloon and the oxygen and carbon dioxide content analysed on a Beckman OM-11 Oxygen Analyser and a Godart Capnograph, respectively. These were linked to an on-line dedicated acquisition system using a pace microprocessor. Instruments were calibrated against gases of known concentrations. The system was flushed from the 26 th to the 29th minutes with the actual gas collection between the 29th and 30th minutes.

Resting HR was determined from the beginning to the end of the 29th minute using electrocardiograph (ECG) chest electrodes placed appropriately for an $\mathrm{MV}_{5}$ trace and a Philips Cardiopan 531 ECG.

The Balke continuous multi-stage treadmill protocol (Consolazio et al, 1963) was modified and employed to determine a direct measure of oxygen consumption at the various $\mathrm{HR}$, and $\mathrm{VO}_{2}$ max. Subjects walked at a rate of 1.53 $\pm 0.06 \mathrm{~m} . \mathrm{s}^{-1}$ for the entire test and the test was begun at zero per cent grade. At the end of the first minute the per cent grade was increased $2 \%$ and at the end of succeeding minutes the grade was increased by $1 \%$ intervals. The test was terminated when the subjects reached maximal physical exhaustion or ceased voluntarily. A ParkinsonCowan dry gasometer was used to measure pulmonary ventilation while a Beckman Microcatheter Sample Pump drew $1000 \mathrm{ml}$ expired air samples continuously from a mixing box. Expired gas samples were analysed in the same manner as for resting metabolism. Heart rates were monitored with an electrocardiograph during the last 10 seconds of each minute for the test duration.

The second session involved the collection and recording of heart rate data via telemetry during simulated competitive dance sequences of Modern and Latin American dance. A Sieman's Telecust 36-S1 Transmitter and Sieman's Telecust 36-S2 Transmitter were attached to a belt and worn around the waist by males and females respectively. The transmitters were connected to three ECG chest electrodes positioned for an $M_{5}$ ECG trace. Individual telemetry systems (Sieman's Telecust 36-E1 Six-Channel Receiver for males and a Sieman's Telecust 36-E2 SixChannel Receiver for females) set on different frequencies and linked to individual ECG recorders were used for each member of each couple.

Dance sequences were chosen randomly and, after dressing in the appropriate costume, subjects were instructed to rest for 30 minutes. A resting HR was taken during the 29th and 30th minutes. Couples then danced either the Modern or Latin American dance sequence with a 15 to 20 second break between each dance to simulate the competitive situation. The Modern dance sequence consisted of: Modern Waltz, Tango, Foxtrot, Quickstep and Viennese Waltz. The order of the Latin American sequence was: Samba, Rumba, Paso Double, Cha Cha and Jive. Dances were completed in accordance with the Australian Dancing Board of Control Regulations for championship and competitive performances (1977) and all couples danced to the same music. HR signals were monitored for 5 seconds out of 15 seconds of each dance throughout the entire routine.

On completion of the first dance sequence, subjects changed costumes and rested for a further thirty minutes. Procedures were then repeated for the second dance sequence.

\section{Statistical Analysis}

The ranges, means and standard deviations of the variables for males and females were computed. Linear regression equations were calculated from the direct measures of $\mathrm{VO}_{2}$ at the various $\mathrm{HR}$ for each minute of the maximal treadmill test in order to predict gross energy expenditures while dancing from those direct measures. Predicted net values were determined by subtracting resting metabolism from predicted gross measures.

A two-way univariate analysis of variance with repeated measures on the dance factor was applied to all variables. For all main effects and interactions, a confidence level of 0.05 was adopted.

\section{RESULTS AND DISCUSSION}

Mean resting and maximal data for $\mathrm{HR}$ and $\mathrm{VO}_{2}$ are reported in Table II. Both males and females were found to have a greater $\mathrm{VO}_{2}$ max in $\mathrm{ml} \mathrm{kg}^{-1} \mathrm{~min}^{-1}$ than those reported by De Guzman (1979) for the corresponding general population of people living in the United States (males 42$50 \mathrm{ml}^{.} \mathrm{kg}^{-1} \mathrm{~min}^{-1}$; females $35-40 \mathrm{ml}^{.} \mathrm{kg}^{-1} \mathrm{~min}^{-1}$ ).

\section{TABLE II}

Mean ( \pm SD) resting and maximal values of heart rate and oxygen consumption

\begin{tabular}{|c|c|c|}
\hline & Males $(n=10)$ & Females $(n=10)$ \\
\hline Resting HR & $55.0 \pm 6.0$ & $63.0 \pm 4.0$ \\
\hline Resting $\mathrm{VO}_{2}$ (L. $\min ^{-1}$ ) & $0.3 \pm 0.05$ & $0.2 \pm 0.02$ \\
\hline Maximal HR (beats. $\min ^{-1}$ ) & $197.0 \pm 6.0$ & $195.0 \pm 10.0$ \\
\hline Maximal $\mathrm{VO}_{2}$ (L.min-1) & $3.2 \pm 0.4$ & $2.4 \pm 0.2$ \\
\hline Maximal $\mathrm{VO}_{2}\left(\mathrm{ml}^{2} \mathrm{~kg}^{-1} \mathrm{~min}^{-1}\right)$ & $52.5 \pm 5.2$ & $42.0 \pm 4.6$ \\
\hline
\end{tabular}

The mean HR data observed for males and females for each individual dance and the overall dance sequences of Modern and Latin American dance are presented in Table III. Exercise which results in a HR range in excess of $\mathbf{1 5 0}$ beats. min-1 $^{-1}$ has been classified as heavy (Suggs, 1967) or extremely heavy (Åstrand and Rodahl, 1977). In this study, males elicited an overall mean HR of 170 beats. min $^{-1}$ (range

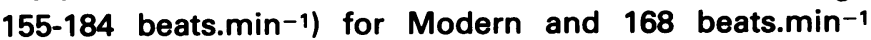
(range 145-183 beats. min $^{-1}$ ) for Latin American sequences. The female overall mean HR for the Modern sequence was

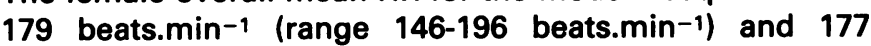
beats. in $^{-1}$ (range 142-193 beats. $\mathrm{min}^{-1}$ ) for the Latin American sequence. According to the above definitions, therefore, competitive Ballroom dancing is a vigorous 
activity requiring the cardiovascular system to work at levels which require high energy expenditures to match this physiological strain. A lack of interaction between cell means indicated that both forms of dance sequence taxed the cardiovascular system equally for both males and females.

\section{TABLE III}

Mean ( $\pm 25 E$ ) heart rate per dance and overall mean heart rate per 5-dance sequence during Modern and Latin American dance

\begin{tabular}{|c|c|c|c|c|c|}
\hline & \multicolumn{2}{|c|}{ Males $(n=10)$} & \multicolumn{3}{|c|}{ Females $(n=10)$} \\
\hline & $\begin{array}{c}\text { Mean HR } \\
\text { (beats. } \min ^{-1} \text { ) }\end{array}$ & 2SE & $\begin{array}{c}\text { Mean HR } \\
\text { (beats. } \min ^{-1} \text { ) }\end{array}$ & & 2SE \\
\hline Waltz & 153 & \pm 6 & 158 & \pm 1 & 11 \\
\hline Tango & 169 & \pm 7 & 171 & \pm & 11 \\
\hline Foxtrot & 168 & \pm 8 & 171 & \pm & 11 \\
\hline Quickstep & 178 & \pm 8 & 182 & \pm & 9 \\
\hline Viennese Waltz & 181 & \pm 9 & 185 & \pm & 9 \\
\hline Overall Modern sequence & 170 & & 173 & & \\
\hline Samba & 158 & \pm 6 & 170 & \pm & 8 \\
\hline Rumba & 158 & \pm 9 & 168 & \pm & 12 \\
\hline Paso Double & 172 & \pm 9 & 181 & \pm & 11 \\
\hline Cha Cha & 176 & \pm 9 & 182 & \pm & 12 \\
\hline Jive & 178 & \pm 10 & 186 & \pm & 11 \\
\hline $\begin{array}{l}\text { Overall Latin American } \\
\text { sequence }\end{array}$ & 168 & & 177 & & \\
\hline
\end{tabular}

The overall mean dancing $H R$ as a percentage of maximal HR for both forms of dance are given in Table IV. Observed mean percentages for males were $86 \%$ for Modern (range $76-93 \%$ ) and $85 \%$ for Latin American (range $71-92 \%)$. The corresponding female values were $89 \%$ for Modern (range $76-97 \%$ ) and $91 \%$ for Latin American (range 74-95\%). Such values further emphasised the physiological strain placed on the cardiovascular system during competitive dancing. The observed F-ratio failed to reach the value required for significance indicating that the percentage of maximal HR attained during both dance sequences is similar and independent of the sex factor.
TABLE IV

Overall mean ( \pm SD) heart rate as a percentage of maximal heart rate

\begin{tabular}{lcc}
\hline & Males $(n=10)$ & Females $(n=10)$ \\
Modern & $86 \pm 5$ & $88 \pm 6$ \\
Latin American & $85 \pm 7$ & $91 \pm 6$ \\
\hline
\end{tabular}

Dancing at a HR in excess of $80 \%$ maximal $H R$ is likely to elicit a physiological training effect (Åstrand and Rodahl, 1977).

The individual overall mean HR for Modern and Latin American dance sequences were substituted into individual regression equations to provide a prediction of the gross oxygen consumption (L.min-1) per dance sequence for males and females. Predicted mean gross and net values of $\mathrm{VO}_{2}$ in L.min-1, ml.kg-1 min-1 and as a percentage of $\mathrm{VO}_{2}$ max and energy expenditure in $\mathrm{kJ} \cdot \mathrm{min}^{-1}$ are summarised in Tables V and VI.

Astrand and Rodahl (1977) classified exercise as heavy if it requires an oxygen uptake range of 1.0 to 1.5 L.min-1; very heavy when 1.5 to 2.0 L.min $^{-1}$ of oxygen are consumed, and extremely heavy if oxygen consumption is in excess of 2.0 L.min-1.

Examination of Tables $\mathrm{V}$ and $\mathrm{VI}$ revealed that males were in excess of 2.0 L.min-1 for both mean gross and mean net values of predicted $\mathrm{VO}_{2}$ during the Modern and Latin American sequences, signifying that competitive Ballroom dancing is an extremely heavy exercise according to the above definition. The only female predicted mean $\mathrm{VO}_{2}$ value which was in excess of 2.0 L.min ${ }^{-1}$ was that of the mean gross $\mathrm{VO}_{2}$ during the Latin American sequence 12.07 L.min-1), which was also classified as extremely heavy by the same definition (Åstrand and Rodahl, 1977). The remaining predicted mean gross and net values of $\mathrm{VO}_{2}$ in L.min-1 were less than 2.0 L.min-1. Thus competitive Ballroom dance can generally be classified as a heavy activity for females.

No significant interaction occurred within cell means for gross and net values, signifying that males required the

TABLE V

Predicted mean ( \pm SD) gross and net values of oxygen consumption and estimated energy expenditure during the Modern dance sequence

\begin{tabular}{|c|c|c|c|c|c|c|c|c|}
\hline \multirow[b]{2}{*}{ Subjects } & \multicolumn{4}{|c|}{ Predicted Mean Gross Values } & \multicolumn{4}{|c|}{ Predicted Mean Net Values } \\
\hline & $\begin{array}{c}\mathrm{VO}_{2} \\
\text { L. } \mathrm{min}^{-1}\end{array}$ & $\begin{array}{c}\forall O_{2} \\
\text { ml.kg-1 } \text { min-1 }^{-1}\end{array}$ & $\% \mathrm{VO}_{2} \max$ & kJ.min ${ }^{-1}$ & $\begin{array}{c}\mathrm{vo}_{2} \\
\text { L. } \mathrm{min}^{-1}\end{array}$ & $\begin{array}{c}\mathrm{VO}_{2} \\
\mathrm{ml} \cdot \mathrm{kg}^{-1} \mathrm{~min}^{-1}\end{array}$ & $\% \vee \mathrm{O}_{2} \max$ & kJ. $\min ^{-1}$ \\
\hline Males & 2.6 & 42.8 & 82.3 & 54.1 & 2.3 & 38.3 & 73.5 & 48.3 \\
\hline$(n=10)$ & \pm 0.4 & \pm 5.7 & \pm 8.0 & \pm 8.1 & \pm 0.4 & \pm 5.7 & \pm 8.4 & \pm 7.8 \\
\hline Females & 2.0 & 34.7 & 82.8 & 41.6 & 1.7 & 30.4 & 73.6 & 36.4 \\
\hline$(n=10)$ & \pm 0.1 & \pm 3.8 & \pm 6.9 & \pm 2.9 & \pm 0.2 & $\pm \mathbf{3 . 3}$ & \pm 6.4 & $\pm \mathbf{3 . 0}$ \\
\hline
\end{tabular}

TABLE V

Predicted mean ( \pm SD) gross and net values of oxygen consumption and estimated energy expenditure during the Latin American dance sequence

\begin{tabular}{|c|c|c|c|c|c|c|c|c|}
\hline \multirow[b]{2}{*}{ Subjects } & \multicolumn{4}{|c|}{ Predicted Mean Gross Values } & \multicolumn{4}{|c|}{ Predicted Mean Net Values } \\
\hline & $\begin{array}{c}\mathrm{VO}_{2} \\
\text { L.min }\end{array}$ & $\begin{array}{c}{v O_{2}}_{\text {ml. } \mathbf{k g}^{-1} \min ^{-1}}\end{array}$ & $\% \mathrm{VO}_{2} \max$ & kJ.min-1 & $\begin{array}{l}\mathrm{VO}_{2} \\
\text { L. } \min ^{-1}\end{array}$ & $\begin{array}{c}\mathrm{VO}_{2} \\
\mathrm{ml} . \mathrm{kg}^{-1} \min ^{-1}\end{array}$ & $\% \mathrm{VO}_{2} \max$ & kJ.min ${ }^{-1}$ \\
\hline Males & 2.6 & 42.8 & 81.9 & 54.0 & 2.3 & 38.2 & 73.0 & 48.2 \\
\hline$(n=10)$ & \pm 0.4 & \pm 6.9 & \pm 2.3 & \pm 9.6 & \pm 0.4 & \pm 6.9 & \pm 8.9 & \pm 9.2 \\
\hline Females & 2.1 & 36.1 & 85.9 & 43.2 & 1.8 & 31.8 & 75.6 & 38.1 \\
\hline$(n=10)$ & \pm 0.05 & \pm 4.1 & \pm 4.0 & \pm 3.3 & \pm 0.2 & \pm 3.7 & \pm 4.2 & \pm 3.6 \\
\hline
\end{tabular}


same absolute value of oxygen whether they danced the Modern or Latin American dance sequences. This was also the case for females. Significant $F$ ratios for predicted gross and predicted net values ( $p<0.001$ ) were, however, observed between cell means indicating that females required substantially lower absolute values of oxygen than did males. Explanation of this is related to the fact that females have a $\mathrm{VO}_{2}$ max some $20-25 \%$ lower than males (Drinkwater, 1973) which is attributed to a lower haemoglobin concentration within the blood for oxygen transport (Åstrand and Rodahl, 1977), lower blood volume or lower heart volume.

Statistical analysis revealed no significant interaction within cell means but a significant difference on the main effects between cell means for mean predicted gross and net $\mathrm{VO}_{2}$ in $\mathrm{ml} \mathrm{kg}^{-1} \mathrm{~min}^{-1}$. This indicated that both the dance sequences required similar levels of oxygen consumption in relation to body weight, but a sex difference was found to exist which was largely a result of the females' higher content of adipose tissue (Åstrand and Rodahl, 1977).

Both the males and females performed at the same percentage of $\mathrm{VO}_{2}$ max during the Modern sequences. This style of dance requires couples to remain in close contact while performing precise, controlled, co-ordinated movement patterns which tend to complement each other. The slightly higher but insignificant values of dancing $\mathrm{VO}_{2}$ as a percentage of $\mathrm{VO}_{2}$ max recorded by females during the Latin American sequence could be associated with a greater variation in movement patterns and floor craft than occurs in Modern dance.

Dancing in excess of $80 \%$ of $\mathrm{VO}_{2}$ for gross measures, as was observed for males and females during both dance sequences in the present study (see Tables $\mathrm{V}$ and $\mathrm{VI}$ ), should provide a physiological training effect (Åstrand and Rodahl, 1977) and improve anaerobic threshold levels (Ekblöm et al, 1968). Thus, when working in practical sessions, regular breaks should be interspersed for technique correction and to avoid excessive fatigue. Conversely, as overload is an important feature of training (Åstrand and Rodahl, 1977), dancers should at times simulate or exceed competition demands in terms of dancing for a time equal to or greater than that required in competition, so that they are well-prepared physiologically for the competition.

Analysis of the mean gross and mean net energy expenditures in $\mathrm{kJ} . \mathrm{min}^{-1}$ revealed that whether the males performed either Modern or Latin American dance they expended equivalent amounts of energy. This was also found to be the case for the females, which indicated that the energy release in gross and net values was equally demanding for both dance styles (See Tables V and VI). A sex difference $(p<0.001)$ for both gross and net energy expenditure was evident, with males expending significantly more energy than females. It was shown previously, however, that males and females danced at the same percentage of $\mathrm{VO}_{2}$ max, which merely re-emphasised the fact that males have a higher $\mathrm{VO}_{2}$ than females at the same relative workload (Drinkwater, 1973). Therefore, when $\mathrm{VO}_{2}$ in L.min-1 was converted to kJ.min-1 the same sex difference was anticipated and noted.
Mean gross energy expenditures in $\mathrm{kJ} \cdot \mathrm{min}^{-1}$ indicated that competitive dancing was as demanding as other sporting activities such as basketball (35.83 kJ.min-1), playing squash (42.70 $\left.\mathrm{kJ} \cdot \mathrm{min}^{-1}\right)$ and cross-country running (44.37 kJ.min-1) (Consolazio et al, 1963).

\section{CONCLUSIONS}

The advanced competitive standard of ballroom dancing required all subjects to perform the dance sequences at energy expenditure levels which were classified as heavy to extremely heavy in terms of exercise loading. Their level of performance in competition taxed them physically such that they were working above $80 \%$ of $\mathrm{VO}_{2}$ max. If fatigue is to be avoided and the level of performance maintained dancers need to simulate or exceed competition demands during training.

\section{References}

Anderson, K. L., Shepherd, R. J., Denolin, H., Varnauskas, E. and Masironi, R., 1971. Fundamentals of Exercise Testing. World Health Organisation, Geneva.

Andrews, R. B., 1967 "Estimation of values of energy expenditure rate from observed values of heart rates", Human Factors 9: 581-586.

Astrand, P.-O. and Rodahl, K., 1977. Textbook of Work Physiology. McGrawHill Book Co., Sydney.

Astrand, P.-O. and Saltin, B., 1961 "Oxygen uptake during the first minutes of heavy muscular exercise". Journal of Applied Physiology 16 (6): 971-976.

Blanksby, B. A., Elliott, B. C. and Bloomfield, J., 1973 "Telemetered heart rate responses of middle-aged sedentary males, middle-aged active males and A grade male squash players". The Medical Journal of Australia 2 (Sept. 8): 477-481.

Bowles, C. J. and Sigerseth, P. O., 1968 "Telemetered heart rate responses to pace patterns in the one mile run". Research Quarterly 39 (1): 36-46

Consolazio, C., Johnson, R. and Pecora, L., 1963. Physiological Measurement of Metabolic Functions in Man. McGraw-Hill Book Co., New York.

Datta, S. R. and Ramanathan, N. L., 1969 "Energy expenditure in work predicted from heart rate and pulmonary ventilation". Journal of Applied Physiology 26 (3): 297-302.

De Guzman, J. A., 1979 "Dance as a contributor to cardiovascular fitness and alteration of body composition". Journal of Health, Physical Education and Recreation, April, 88-91.

Drinkwater, B. L., 1973 "Physiological responses of women to exercise" in Exercise and Sports Science Reviews, Vol. 1, Wilmore, J. H. (ed.). Academic Press, New York.

Ekblöm, B., Astrand, P.-O., Saltin, B., Stenberg, J. and Wallström, B., 1968 "Effect of training on circulatory response to exercise". Journal of Applied Physiology 24 (4): 518-525.

Favia, I. E. and Phillips, A., 1970 "A study of telemetred cardiac response of young boys and girls during gymnastics performance". Journal of Sports Medicine and Physical Fitness 10 (3): 145-150.

Maxfield, M. E. and Brouha, L., 1963 "Validity of heart rate as an indicator of cardiac strain". Journal of Applied Physiology 18 (5): 1099-1104.

Molhotra, M. S., Sengupta, J. and Rai, R. M., 1963 "Pulse count as a measure of energy expenditure". Journal of Applied Physiology 18 (5): 994-996.

Ramsey, J. D., Ayoub, M. M., Dudek, R. A. and Edgar, H. S., 1970 "Heart rate recovery during a college basketball game". Research Quarterly 41 (4): 528-535.

Sloan, A. W. and Weir, J. B. dev. 1970 "Nomograms for prediction of body density and total body fat from skinfold measurements". Journal of Applied Physiology 28 (2): 221-223.

Suggs, C. W., 1967 "An analysis of heart rate responses to exercise". Research Quarterly 39 (1): 195-205.

Wyndham, C. H., Strydom, N. B., Maritz, J. S., Morrison, J. F., Peter, J. and Potgeiter, Z. U., 1959 "Maximal oxygen intake and maximal heart rate during strenuous work". Journal of Applied Physiology 14 (6): 927-936.

Yuhasz, M. S., 1962 "The effects of sports training on body fat in man with predictions of optimal body weight". Unpublished Doctoral Dissertation, University of Illinois. 